\title{
REDUÇÃO DA JORNADA DE TRABALHO E QUALIDADE DOS EMPREGOS: ENTRE O DISCURSO, A TEORIA E A REALIDADE ${ }^{1}$
}

\author{
Daniel Gustavo Mocelin
}

\begin{abstract}
RESUMO
O objetivo deste ensaio é examinar o tema da redução da jornada de trabalho de modo crítico, expondo algumas dimensões teóricas e empíricas importantes que costumam ficar excluídas do debate público sobre a matéria. Analisando algumas características sobre o tempo de contratação de trabalhadores no mercado de trabalho brasileiro, demonstra-se que existe uma grande distância entre o discurso, a leitura acadêmica sobre a matéria e a realidade. A redução da jornada de trabalho é um tema multifacetado, que caracteriza um debate complexo e polêmico, suscitando o interesse de diversos agentes sociais interessados nessa pauta, mas que possuem diferentes concepções acerca do debate, em razão da heterogeneidade de valores em jogo. Argumenta-se no artigo que as implicações sociais de uma medida política de redução da jornada de trabalho não podem ser previstas. Contudo, entende-se que essa redução é uma tendência histórica, vinculada ao desenvolvimento socioeconômico. Há diferenças marcantes entre o discurso sindical, a simpatia política pela medida, as afirmações teóricas e as evidências empíricas sobre a temática. O ensaio aborda o tema sobre duas dimensões principais: quantidade $e$ qualidade do emprego. Quando tratado pela perspectiva da quantidade do emprego, envolve a questão da geração de empregos, a fim de minimizar os efeitos do desemprego. Quando tratado pela perspectiva da qualidade do emprego, envolve a questão da riqueza das atividades laborais e o melhor rendimento, proporcionando real melhoria nas condições laborais e na qualidade de vida dos trabalhadores.
\end{abstract}

PALAVRAS-CHAVE: redução da jornada de trabalho; emprego; qualidade do emprego.

\section{INTRODUÇÃO}

Em 28 de maio de 2008, centrais sindicais em todo o Brasil mobilizaram-se para sugerir a "redução da jornada de trabalho, sem redução dos salários"; proposta que parece bem vista pelo governo federal. Os sindicalistas, inclusive, têm pressionado o governo: diversas centrais sindicais (entre elas, Central Única dos Trabalhadores, Força Sindical, Central Geral dos Trabalhadores do Brasil, Social Democracia Sindical e Central Autônoma dos Trabalhadores) iniciaram uma coleta de assinaturas, para que o Congresso Nacional agilizasse o processo de votação, na Câmara dos Deputados. Deste então, o debate público sobre a matéria está em pauta, mas não avançou de forma decisiva.

\footnotetext{
1 Durante a realização deste trabalho, o autor contou com o apoio institucional da Coordenação de Aperfeiçoamento de Pessoal de Nível Superior (Capes).
}

O impacto social de uma medida como a redução da jornada de trabalho pode vir a ser social e economicamente significativo, mas pode seguir diversos caminhos e assumir resultados diferentes, dependendo do período histórico e do contexto cultural e institucional em que ocorre. Para aprofundar essa discussão, exige-se uma atenção maior sobre o sentido de tal medida, conhecendo sua evolução histórica, seja como medida política, seja como resultado do desenvolvimento econômico e das relações sociais. Um "espectro obscuro" tende a rondar essa discussão, especialmente quando ela não vem acompanhada de um embasamento mais científico, com fundamentação teórica e evidências empíricas consistentes. Há diferenças marcantes entre o discurso sindical, a simpatia política pela medida, as afirmações teóricas e as evidências empíricas sobre a temática.

O objetivo deste ensaio é examinar o tema da redução da jornada de trabalho de maneira crítica, 
expondo algumas dimensões teóricas e empíricas importantes que costumam ficar excluídas do debate público sobre a matéria.

A expressão "jornada de trabalho" refere-se ao tempo despendido com o trabalho remunerado executado pelo trabalhador para um empregador, mediante um contrato regular de prestação de serviço, que pode ser o tempo diário, semanal, mensal ou anual. Contudo, ao tratar sobre o tema da redução da jornada de trabalho, deve-se estar atento ao conceito de trabalho que está em jogo nesta expressão. Em geral, quando se trata da redução da jornada de trabalho, não se está falando no trabalho em seu sentido antropológico ou genérico, como práxis criativa, no sentido empregado por Marx em seus escritos de juventude. Na verdade, trata-se muito mais do "trabalho no seu sentido moderno"2, ou seja, a relação contratual, o emprego ou a ocupação.

Dessa forma, o debate sobre a redução da jornada de trabalho refere-se à redução das horas que são cumpridas no emprego, em uma relação contratual de trabalho assalariado, subordinado e heterônomo (prestado para um empregador). Portanto, usa-se a expressão "redução da jornada de trabalho" quando se faz referência à "redução de tempo dedicado ao trabalho no emprego", diário, semanal ou mensal. Reduzir a jornada de trabalho não significa necessariamente que as pessoas venham a trabalhar menos, pelo contrário, as pessoas poderão trabalhar mais, mas em atividades por elas escolhidas e sem remuneração, ou seja, em atividades não fundadas exclusivamente na racionalidade econômica ${ }^{3}$. Reduzir a jornada de trabalho significa que as pessoas passariam menos tempo no emprego ou vendendo sua "força-

\footnotetext{
2 Sobre esse debate, ver Méda (1999), Gorz (2003) e Arendt (2005). Esses autores desenvolveram discussões filosóficas sobre o sentido do trabalho na modernidade, especialmente enfocando a crítica sobre a racionalidade econômica que governaria as relações sociais após a revolução industrial.

3 Na modernidade, constata-se uma redução das relações que o homem poderia manter com o mundo (contemplação e ação, por exemplo) em favor de uma relação específica relacionada à produção e ao consumo, o que seria caracterizado por importantes autores como racionalidade econômica. Sobre isso, ver Gorz (2003) e Arendt (2005). Referências a tal questão também estão presentes nas obras clássicas de Max Weber. No final deste ensaio voltaremos ao assunto.
}

de-trabalho". É uma discussão que essencialmente refere-se ao tempo regulado de trabalho. Sabe-se, por exemplo, que um trabalhador altamente qualificado - empregado nas chamadas "atividades laborais criativas", que remuneram melhor - pode ter uma jornada contratada menor que um trabalhador menos qualificado - empregado em uma função mais rotineira. Porém, as exigências relacionadas à qualificação dos primeiros exige um grande dispêndio de tempo e dedicação extrajornada contratada de trabalho, mas as recompensas por isso viriam de maneiras não diretamente vinculadas à jornada de trabalho. Sobre isso, trata-se adiante da relação entre o tamanho da jornada de trabalho e o nível de remuneração no mercado de trabalho formal brasileiro.

O ensaio aborda o tema da redução da jornada de trabalho sobre duas dimensões principais: quantidade e qualidade do emprego. Quando tratado desde a perspectiva da quantidade do emprego, envolve a questão da geração de empregos, para minimizar os efeitos do desemprego. Essa seria a pauta mais recorrente dos debates, especialmente após o movimento de reestruturação produtiva das décadas de 1980 e 1990, mas que ainda está muito presente nos discursos sindicais e políticos. Quando tratado desde a perspectiva da qualidade do emprego, envolve a questão da riqueza das atividades laborais e o melhor rendimento, devido a uma maior valorização social e econômica do trabalho desempenhado, promovendo a melhoria da qualidade de vida dos trabalhadores. Essa seria a pauta mais importante do debate, pois resgataria o cunho histórico da redução da jornada de trabalho, fundado na luta por melhores empregos e, em "menor" importância, na reivindicação por mais empregos. Melhores empregos são ocupados por trabalhadores mais qualificados, com maior grau de instrução, que também são mais valorizados no mercado de trabalho, permitindo um adequado rendimento, mesmo em jornadas menores. $\mathrm{O}$ caso é que a horatrabalho dos profissionais mais qualificados tem maior preço no mercado de trabalho.

O debate público, em maior medida, e a discussão teórica, em menor, sobre a redução da jornada de trabalho esteve recentemente vinculada ao fenômeno do desemprego. Muitas vezes, quando assume caráter de política pública, a redução da jornada de trabalho tem o objetivo de reduzir a taxa de desemprego. Esse debate é conhecido sob a denominação de partilha do trabalho, ou work- 
sharing. A expectativa daqueles que defendem a redução da jornada de trabalho por medida política é a de que a redução de jornada permitiria que o mesmo emprego fosse repartido por mais trabalhadores (todos trabalhando menos horas), o que resultaria, portanto, em mais empregos. No entanto, a viabilidade dessa "partilha do emprego" é questionável. A esperada "redução da jornada com manutenção do salário mensal" tende a aumentar o custo do trabalho frente aos demais fatores de produção, podendo provocar uma eventual substituição do fator trabalho, que ficaria mais caro frente aos demais. Por outro lado, aplicar uma política de redução da jornada de trabalho nas atividades econômicas que demandam trabalho pouco qualificado pode ampliar a geração de empregos precários e de baixa remuneração, empregos facilmente substituíveis por novas tecnologias; haveria mais empregos apenas temporariamente.

A redução da jornada de trabalho caracterizase, portanto, como um tema multifacetado, demarcado por um debate complexo e polêmico, suscitando o interesse de administradores, economista, historiadores, sociólogos, governo, cidadãos, sindicatos, empresários, federações industriais e trabalhadores. Todavia, destaca-se que cada agente interessado possui diferentes concepções acerca do debate, em razão da heterogeneidade de valores em jogo.

\section{DIVERGÊNCIAS E CONTRADIÇÕES ACER- CA DA REDUÇÃO DA JORNADA DE TRA- BALHO}

A partir do final dos anos 1960, o desemprego surgiu como um dos temas centrais das sociedades capitalistas modernas, e talvez caracterize a principal dimensão de análise sobre a problemática da redução da jornada de trabalho. Entretanto, há controvérsias sobre se a geração de empregos é o centro da questão. Várias propostas têm sido apresentadas para combater o problema crônico de escassa geração de emprego. No Brasil, a sugestão das centrais sindicais levantada por sua intelligentsia tem sido pela redução da jornada de trabalho. Segundo o Departamento Intersindical de Estatísticas e Estudos Sócio-Econômicos (DIEESE, 2006), se os ocupados trabalharem menos horas por semana seria possível gerar novos empregos para que mais pessoas possam inserir-se no mercado de trabalho. A idéia, que permeia as centrais sindicais, é a de que se os trabalhadores do setor formal da economia reduzissem sua carga horária, a tendência seria a criação de novos postos de trabalho formais.

Nessa perspectiva, que toma por base o desemprego, a problemática redução da jornada de trabalho aparece como uma questão quantitativa sobre a geração de empregos, sem uma preocupação com o tipo de emprego gerado.

Calvete $(2003$, p. 15) sugeriu que a redução da jornada de trabalho não poderia ser transformada em uma panacéia para o combate ao desemprego. Para o autor, essa política conformaria instrumento útil se adotada no "momento certo" e acompanhada de outras medidas necessárias. Nos marcos do capitalismo atual, para que a redução da jornada de trabalho tivesse algum efeito positivo sobre a geração de novos postos de trabalho, teria de vir acompanhada pela proibição de horas-extras, maior controle sobre a intensidade do trabalho, manutenção dos padrões de cumprimento da jornada de trabalho e cobertura universal dos novos e velhos riscos sociais.

Alguns sindicatos defendem que a redução da jornada forçaria o surgimento de um novo turno de trabalho, com a contratação de novos trabalhadores. Alguns sindicalistas estariam esquecendo-se dos encargos que as empresas pagam por cada trabalhador contratado. Muitas empresas, especialmente as pequenas, não suportariam a contratação de um novo contingente de mão-de-obra e acabariam por falir, podendo gerar mais desemprego. Por isso, empresários sugerem que a redução da jornada de trabalho também deveria vir acompanhada por alguma flexibilização da legislação trabalhista, condição que não costuma ser levantada no discurso sindical. Deve-se destacar ainda que o pagamento de horas-extras acaba sendo menos oneroso às empresas do que o pagamento de horas normais para empregados de um terceiro turno de trabalho, com todos os seus direitos garantidos. No entanto, se as horas-extras fossem tornadas mais caras, esse quadro poderia tornar-se diferenciado. Além disso, deve-se considerar que no caso de a legislação "impor" a redução da jornada de trabalho, haveria o risco de ocorrer a criação de um novo turno de trabalho apenas naquelas empresas com trabalho monótono e repetitivo, ou seja, acabariam sendo criados empregos de menor ou baixa qualidade, visto que trabalhadores mais qualificados, que ocupam melhores postos de trabalho, já têm jornada média menor. 
De acordo com estudos feitos pelo Dieese (2007) a redução da jornada de 44 para 40 horas semanais poderia gerar mais de dois milhões de novos empregos, se acompanhada do fim das horas-extras. O estudo supõe que essas quatro horas reduzidas por jornada seriam ainda necessárias para as empresas manterem o mesmo nível de produtividade. Assim, as empresas teriam de contratar mais, e essas quatro horas ficariam disponíveis para outro trabalhador.

Muitas vezes, os defensores da redução da jornada esquecem que, no caso do Brasil, as condições de emprego são desfavoráveis principalmente nas atividades menos intensivas em tecnologia ou para trabalhadores de baixa escolarização, com rendimentos insuficientes. Então seria preciso estar atento para não efetivar uma medida que venha a beneficiar mais aqueles já privilegiados. A redução da jornada para trabalhadores que têm baixos salários pode significar redução ainda maior do salário, visto que a natureza de sua atividade, por si mesma, tende a ser pobre em conteúdo e pouco valorizada. Enquanto isso, os melhor remunerados seriam beneficiados, pois trabalhariam menos horas e não teriam perdas significativas de salário, considerando que, ao contrário dos primeiros, suas atividades laborais são ricas e valorizadas no mercado de trabalho. O fato é que a possível redução do salário-hora de quem ganha mais faria menor diferença do que uma redução no salário-hora de quem recebe menos.

Outro ponto de divergência refere-se aos efeitos sobre a economia. Os agentes que são contrários à redução da jornada de trabalho entendem que essa medida poderia causar um colapso na economia, já que a reivindicação prevê apenas a diminuição das horas trabalhadas e não dos salários. Nesse sentido, o debate sobre a redução da jornada de trabalho poderia ser ponderado no sentido de também ser acompanhado por uma discussão sobre a revisão do nível de remuneração, pois distribuir o tempo de trabalho também significa pensar na redistribuição da renda do trabalho.

Muitos sindicatos estão atentos a outros elementos que intercalam esse debate. Quando os sindicatos defendem a idéia de que a redução da jornada seria fator potencial da geração de empregos, refletem, ao mesmo tempo, que essa redução melhoraria a qualidade de vida do trabalhador, que passaria a dispor de mais tempo livre para o lazer, educação e família. Muitos dos estudos apresentados adiante destacam que a redução da jornada de trabalho não gera necessariamente novas vagas.

Defensor da redução da jornada de trabalho, Calvete (2003) reconhece que essa medida não pode vir a caracterizar um instrumento da precarização das condições de trabalho. Diminuição de salários, flexibilização do horário e perda de benefícios poderiam transformar a redução da jornada em uma extensão do emprego por tempo parcial. Como defende o autor, o que seria benéfico para a economia e para todos os agentes seria que a redução da jornada mantivesse as condições e os benefícios do emprego, ou seja, com a manutenção do trabalho em tempo integral, porém com jornada menor. Em pesquisa de doutorado, Calvete (2006) concluiu que a redução da jornada pode ser um instrumento útil se adotada em período de crescimento econômico e acompanhada de outras medidas, que potencializem seus resultados, tais como maior limitação da utilização de horas-extras, maior controle sobre a intensidade do trabalho, regras mais rígidas no banco de horas, melhoria na fiscalização pelas delegacias regionais do trabalho e maiores restrições às contratações atípicas.

O debate acadêmico metodologicamente mais rigoroso sobre a redução da jornada de trabalho permeia diversos aspectos, tais como os contratos flexíveis, por meio de compensação de horas, o trabalho a domicílio, a extinção do controle de horário (TIETZE \& MUSSON, 2002; KARSTEN \& LEOPOLD, 2003); também é vastamente recorrente como uma medida que favorece a distribuição de renda e o aumento da produtividade (BOSCH \& LEHNDORFF, 2001); ou como a expressão da uma pauta histórica da classe trabalhadora (DAL ROSSO, 2002; CALVETE 2006); também como aspecto alinhado com a caracterização do "trabalho decente", neste caso, considerando-se as jornadas demasiado longas e sem aval legal, que tendem a ser recorrentes no mercado de trabalho informal, especialmente nos países mais pobres (BESCOND, CHÂTAIGNIER \& MEHRAN, 2003; GHAI, 2003). Tem-se apontado, por exemplo, que a redução da jornada de trabalho pode ter impactos sobre a vida dentro e fora do trabalho, melhorando a qualidade de vida no trabalho (CARNEIRO \& FERREIRA, 2007). Há autores que demonstram ser a redução da jornada 
de trabalho uma tendência histórica atrelada ao desenvolvimento socioeconômico (DAL ROSSO, 1998; 2002; 2006). Por outro lado, não se pode deixar de destacar ainda aqueles autores que alertam sobre a "necessidade" dessa medida, reproduzindo o discurso sindical (DIEESE, 2006; 2007; e, mais ponderado, CALVETE, 2003; 2006).

Conhecer de antemão se os resultados de uma medida como a redução da jornada de trabalho seriam positivos depende de uma série de fatores sociais e econômicos de difícil mensuração. Os agentes diretamente atingidos, beneficiados ou não pela medida, como o trabalhador, o meio empresarial e o governo, estão frente a mudanças que podem originar "conseqüências impremeditadas", que poderiam, inclusive, assumir efeitos contrários ao que se espera. Cabe ainda questionar a necessidade da "geração forçada" de novos empregos, considerando o caso recente do Brasil, quando houve geração de mais de 13 milhões de empregos formais, entre 2000 e 2008. Portanto, não se sabe bem ao certo as implicações sociais de tal medida caso seja politicamente determinada; o que se sabe é que ressurge um grande debate sobre o assunto e que a redução da jornada de trabalho é uma tendência histórica.

De qualquer forma, quanto mais os principais agentes interessados estiverem envolvidos no debate, maiores são as chances de os resultados serem positivos. Do contrário, a falta de diálogo entre as partes interessadas poderá não causar o efeito esperado, seja a geração de mais empregos ou a melhoria das condições laborais e da qualidade de vida dos trabalhadores.

No caso do mercado de trabalho brasileiro, em que ainda há concentração acentuada de postos de trabalho de baixa remuneração, que demandam trabalho pouco qualificado, em que as atividades laborais são empobrecidas, a questão antes descrita poderia ter um agravante. Poder-se-ia acabar procedendo à redução do tempo de trabalho sem melhorar as condições de emprego. Dal Rosso (2002) aponta três medidas do tempo que influenciam a relação entre homem e trabalho: a duração (quantidade de horas por dias, semanas ou anos), a distribuição (forma como o horário concentra-se ou dilui-se em determinados períodos) e a intensidade (esforço físico, intelectual e emocional investido no trabalho).

Carneiro e Ferreira (2007) buscaram analisar possíveis impactos da redução de jornada de tra- balho sobre a qualidade de vida no trabalho, abordando esta última especialmente quanto à compatibilização da vida pessoal com o trabalho e ao aproveitamento do tempo no trabalho, a partir do caso de uma organização pública brasileira. No estudo, identificaram pouca relação entre a redução da jornada e a qualidade de vida no trabalho, contrariando o que afirmam peremptoriamente a literatura favorável e os sindicalistas sobre os benefícios em termos de qualidade de vida no trabalho e "trabalho decente". O uso de escalas psicométricas adotadas pelos autores revelou pouca diferença nos indicadores de qualidade de vida entre os empregados em jornada reduzida e jornada convencional. Nas entrevistas, apontaram que empregados em jornada reduzida e gestores relataram haver melhor uso do tempo, pois conseguiam resolver assuntos no período livre do dia, e que sua produtividade manteve-se ou melhorou; entretanto, os gestores queixaram-se de ser mais difícil supervisionar a equipe. A redução da jornada propiciou melhor ajustamento entre vida profissional e particular, oferecendo tempo para cuidados com a saúde, família e outros assuntos. Uma relevante constatação do estudo foi que houve melhoria da "qualidade de vida 'fora' do trabalho", com mais tempo para dedicar-se à família, à saúde e a outras atividades. O estudo revelou algumas melhorias específicas na qualidade de vida no trabalho, tais como melhor aproveitamento do tempo e concentração, contudo, pouco ou nada melhoraram os indicadores das condições laborais e das relações sociais de trabalho, nem mesmo aumentou o número de vagas disponíveis.

A situação européia é distinta do contexto brasileiro, mas alguns aspectos são convergentes para a compreensão do contexto em que se concebe a idéia da redução da jornada de trabalho. Considerando-se a experiência francesa, Estrade, Méda e Orain (2001) constataram que os impactos sobre a vida profissional e familiar variam conforme as organizações, o gênero do trabalhador, a natureza da atividade laboral e os cargos técnicos ou gerenciais. Os autores constaram mais uma melhora na relação entre vida privada e vida no trabalho do que propriamente qualquer alteração nas condições de trabalho, remuneração ou satisfação. Ainda sobre o caso francês, Pélisse (2004) destaca que novas práticas de uso do tempo no trabalho emergiram com a redução de jornada, como a modulação, quando gestores definem os períodos de trabalho das equipes conforme a de- 
manda, o trabalho em turnos com revezamento e o rearranjo permanente de equipes de trabalho.

No debate dos anos 1980 sobre a redução da jornada de trabalho, o aspecto mais sustentado foi o da geração de empregos, tendo em vista a crise econômica internacional e a reestruturação produtiva, que indicava forte redução no número de empregos. No debate dos anos 1990, um aspecto (re)incluído foi o da melhoria na qualidade de vida do trabalhador, na forma de mais horas livres para o lazer, a educação, a cidadania e a qualificação profissional. Hoje, ambos os aspectos são importantes, mas também há quem sustente que uma jornada de trabalho mais reduzida possa inclusive gerar maior produtividade.

Entre os argumentos dos que acreditam que a redução da jornada de trabalho pode servir como um mecanismo que ajude a diminuir os altos índices de desemprego, estão os dados da Organização Internacional do Trabalho (OIT), que mostram e comparam a jornada semanal de trabalho em horas. Nos países mais desenvolvidos, a jornada de trabalho declinou gradualmente dos anos 1980 aos anos 2000: nesse período, houve uma redução média na duração da jornada de trabalho de 44 para cerca de 38 horas semanais, o que foi seguido por uma forte ampliação do emprego em atividades de serviços e comércio. Contudo, nos países menos desenvolvidos ou periféricos, onde se expandiu a indústria fabril mais tradicional, as jornadas estariam diminuindo em menor ritmo.

Nos estudos recentes, a flexibilidade foi foco importante dos estudos sobre a redução da jornada de trabalho, embora tenha sido ponderada em tons distintos. Bosch (1999), por exemplo, argumenta que a redução da jornada de trabalho acaba sendo uma política e uma prática virtuosa especialmente quando o ambiente de aplicação atinge uma "maturidade econômica". Quer dizer, quando os trabalhadores suprem suas necessidades exclusivamente com sua remuneração, recebida em razão de uma menor jornada, sem que seja necessário que eles venham a cumprir horas-extras ou ter mais de um emprego, caso de economias altamente desenvolvidas, especialmente onde há a consolidação de um Estado de bem-estar social e economia dinâmica.

Por outro lado, há estudos que consideram que o aumento da flexibilidade possibilita um maior controle sobre o tempo de trabalho e mesmo a extensão de jornada não remunerada de trabalho
(BOSCH \& LEHNDORFF, 2001; SINGE \& CROUCHER, 2003). No Brasil, Dal Rosso (2003) e Carneiro e Ferreira (2007) mencionam o caso das práticas de "banco de horas", que ganharam espaço sob o argumento de que permitia melhor conciliação entre vida pessoal e profissional. Segundo os autores, a regulamentação do banco de horas veio sendo impulsionada mais pelos interesses dos empresários, resultando em aumento de horas trabalhadas e redução de custos com horas-extras, mesmo que pareça ser uma prática que agrade os trabalhadores.

Outros estudos com sólida base empírica têm revelado ainda que diversos fatores podem influenciar a percepção do trabalhador sobre o tamanho da jornada de trabalho: a idade indica o "momento da vida", associando-se à constituição de família, investimento em qualificação profissional e proximidade da aposentadoria (TIETZE \& MUSSON, 2002; KARSTEN \& LEOPOLD, 2003; SINGE \& CROUCHER, 2003); a perspectiva de progressão na carreira, comprometimento organizacional, motivação e satisfação com o trabalho, impacto sobre o ritmo de trabalho (WALSH \& DEERY, 1999); conciliação com vida social e do lazer com a profissional (ESTRADE, MÉDA \& ORAIN, 2001); o resultado para a renda familiar (BOSCH, 1999).

As concepções teóricas sobre a redução da jornada de trabalho proferem afirmações mais categóricas, permeando elementos mais complexos que aqueles levantados pelo debate público e por isso diferem das proferidas por governos e sindicalistas, atacando, inclusive, aspectos mais amplos apontados por autores que embasam seus argumentos em dados empíricos. Deve-se destacar, entretanto, que os teóricos de maior destaque, tanto os mais antigos quanto os atuais, adotam pressupostos que têm por base, em geral, a realidade social e econômica dos países mais desenvolvidos.

A polêmica em torno da redução da jornada de empregos é tão antiga quanto o capitalismo. A revolução industrial marcou uma era em que o trabalho assumiu uma posição de destaque na sociedade moderna e na vida das pessoas. Desde então, debates sobre essa realidade despertaram o interesse de muitos pensadores. Em muitos destes debates, a jornada de trabalho foi tema recorrente. Abordagens mais críticas defenderam que a configuração da jornada de trabalho passou a 
ser um fator de extrema importância para os ganhos do capital. Em O Capital, Karl Marx apontou o tamanho da jornada de trabalho, associada a outros fatores - introdução de novas tecnologias mecânicas ao processo de trabalho, por exemplo - como um dos motores do capitalismo. Era com o alargamento da jornada de trabalho que o capitalista obtinha a mais-valia absoluta. Estava na extração da mais-valia o principal mecanismo ao mesmo tempo de acumulação de capital e de exploração dos trabalhadores.

Guy Aznar (1995) e André Gorz (2004) são dois defensores da necessidade de "trabalhar menos para trabalharem todos". Para esses autores, o trabalho de tempo integral difundido durante o período industrial, de 1850 a 1975 , tem reduzido nas economias mais desenvolvidas. Frente a esse fato, ambos argumentam que o emprego em tempo integral não existe mais em quantidade suficiente e, por isso, o emprego teria perdido o caráter de provedor das necessidades humanas e dos direitos sociais. Da mesma forma, entendem que frente aos padrões atuais de produção e de consumo, nenhuma ação isolada seria suficiente para retomar o "pleno emprego", como esse existiu nos países mais desenvolvidos da Europa ocidental no pós-segunda guerra. Parece evidente que a redução da jornada de trabalho precisaria ser acompanhada de outras medidas como o crescimento econômico, ampliação da produtividade e uma mudança cultural.

Gorz e Aznar defendem que está em andamento uma revolução cultural que reconhece a necessidade da redistribuição do tempo de trabalho e a redução do tempo de trabalho individual como parte de uma mudança efetiva da sociedade. Contudo, classificam como irreal e insuficiente a simples redução da jornada de trabalho por meio de uma medida política, sem uma revolução cultural e uma mudança na organização da sociedade.

O sociólogo alemão Claus Offe $(1994 ; 1997)$ entende que o futuro não estaria em trabalhos seguros, duradouros, com expediente integral, mas na relação de alternância entre períodos de trabalho pago cada vez mais curtos e períodos sempre maiores de atividade livre. Assim, o prestígio e o reconhecimento, obtidos por meio do trabalho assalariado, poderiam ser deslocados para as atividades pessoais. $\mathrm{O}$ autor chega a sugerir que todas as pessoas, durante todo o seu período de vida útil de trabalho, poderiam ter grandes licen- ças do trabalho, até mesmo anos de férias garantidas e pagas. Neste sentido concorda com Gorz, para quem o capital humano - riqueza de ideias, criatividade, capacidade de aprendizagem - estaria tornando-se mais importante que o capital material no novo capitalismo; o capital humano ainda representaria pequena fração do tempo usado pela força de trabalho para a sua produção e reprodução. Para Offe e Gorz, a capacidade de independência das pessoas pode ser constituída por meio da aquisição constante do conhecimento.

Para Robert Castel (1998) o fenômeno do desemprego não faz parte de uma crise passageira e, por essa razão, não pode ser superado com ações conjunturais. $\mathrm{O}$ foco do autor recai sobre outro fenômeno, que seria a precarização do trabalho. Tanto o desemprego quanto a precarização do trabalho caracterizariam fenômenos conjuntos da dinâmica da modernização e reestruturação produtiva que ocorreu nas décadas de 1980 e 1990. Em sua obra, o autor descreve e analisa a decadência da sociedade salarial e a consequente redução das proteções sociais, da propriedade social e dos direitos trabalhistas. Ao tratar sobre alguns cenários possíveis para o futuro na obra $A s$ metamorfoses da questão social, em um desses o autor sugere a redução da jornada de trabalho como um meio de redistribuir o salário, o tempo de trabalho, as proteções sociais e as garantias jurídicas: "a divisão do trabalho é menos um fim em si do que um meio, aparentemente o mais direto para chegar a uma redistribuição efetiva dos atributos da cidadania social" (idem, p. 583). Contudo, Castel reconhece que a renda do trabalho também deveria ser repartida entre os indivíduos. À redução da jornada de trabalho deve seguir-se também uma redistribuição da riqueza.

Castel defende a tese de que se deveria manter o trabalho como centro estruturador da sociedade e, a partir dele, redistribuir a cidadania e manter a coesão social. Não se trataria efetivamente de restaurar a sociedade salarial, mas sim de mantê-la como referência. Para o autor, a redução da jornada de trabalho é mais que uma questão técnica ou política, em que a dificuldade está em encontrar fórmulas que amenizem ou compensem perdas. A redução da jornada de trabalho seria uma questão de mudança cultural com consequências políticas de fundo. Tomando como exemplo o fracasso na criação de emprego da lei das 39 horas, aplicada na França em 1982, o autor percebeu que soluções não se encontram em 
propostas tímidas ou conciliatórias, mas no enfrentamento cultural do problema político. Para solucionar o problema seria necessária a atualização do direito trabalhista, a redução substancial do tempo de trabalho e a consolidação da cobertura universal dos riscos sociais, que deveriam ser em parte desatrelados do trabalho assalariado.

Robert Castel sugere que uma resposta "consistiria em transferir os direitos do estatuto do emprego à pessoa do trabalhador" (CASTEL, 2005 , p. 84 ; sem grifos no original), restabelecendo uma continuidade dos direitos por meio da descontinuidade das trajetórias profissionais. "Nem o mercado, nem o trabalho, nem o Estado têm hoje a mesma estrutura, mas a questão de sua articulação sempre surge de novo. Ao trabalho que se tornou móvel e ao mercado que se tornou volátil deveria corresponder um Estado social que se tornou flexível” (idem, p. 94).

Entre os teóricos mencionados, a posição mais crítica sobre o sentido da redução da jornada de trabalho foi feita por Gorz (2003, p. 186-187). O autor afirma a necessidade de superar tanto o debate técnico quanto o debate político, avançando para o debate cultural, ao sugerir que se rompa com a noção estritamente econômica vinculada ao trabalho na sociedade capitalista. A redução efetiva da redução da jornada de trabalho corresponderia a uma escolha de sociedade. Dois objetivos estariam vinculados: em primeiro lugar, destaca que todos trabalhariam menos para que todos possam trabalhar e desenvolver fora do seu trabalho as potencialidades pessoais que não conseguem nele desenvolver. Ou seja, na perspectiva de Gorz, a redução da jornada de trabalho não estaria voltada apenas para que todos tenham emprego, pelo contrário, esse seria um ponto de menor importância. A redução da jornada de trabalho estaria condicionada a uma mudança de atitude em relação ao emprego, que não deveria mais ser o centro estruturador da vida das pessoas, mas poderia continuar sendo o centro estruturador da coesão social.

Em segundo lugar, Gorz sugere que uma proporção maior da população possa ascender a tarefas profissionais qualificadas, complexas, criativas, responsáveis, que permitam evoluir e renovar-se continuamente. Ou seja, nem sequer adiantaria reduzir a jornada de atividades laborais que exigem pouca instrução do trabalhador, pois elas tendem a ser substituídas por novas tecnologias, e acabariam por manter o desemprego e não favoreceriam o desenvolvimento pessoal dos trabalhadores nelas empregados. "Quanto mais um trabalhador é qualificado, mais a pessoa que o realiza precisa de tempo para atualizar seus conhecimentos, renovar-se, inovar e manter-se receptivo, diversificando os seus centros de interesse. Isso vale para os professores, os médicos, os cientistas e os técnicos, para os dirigentes de empresa, etc. Isso vale em particular para as empresas de ponta. Para impedir a monotonia e a rotinização da mente, a direção obriga a transferências, rupturas no ritmo de vida, feriados: viagens de estudo, estágios nas filiais do estrangeiro, seminários internacionais, ano sabático. Os estágios, seminários, etc., não têm por finalidade aperfeiçoar o empregado em sua própria especialidade mas, ao contrário, estão o mais das vezes distantes dos interesses imediatos de seu trabalho, para que possam incitar à mudança, ao distanciamento, para investir em um horizonte mais aberto, uma imaginação mais fértil. [...] $\S[\ldots]$ trabalhar menos (em número de horas consagradas ao trabalho profissional direto) é trabalhar melhor, sobretudo nos ofícios inovadores ou em contínua inovação. É, portanto, nestes ofícios que a redução da jornada de trabalho é possível e desejável [...]. Também nesses oficios a atividade pode ser repartida entre um número maior de pessoas" (idem, p. 188-189; grifos no original).

É nesse sentido de crítica à racionalidade econômica que Gorz entende a importância da redução da jornada de trabalho, mas espera junto dessa redução uma maior flexibilidade; não simplesmente uma redução da jornada diária, mas antes uma redução da jornada mensal, anual. Para Gorz, a redução linear do tempo de trabalho, com manutenção de horários cotidianos rígidos e uniformes seria a menos promissora e a menos eficaz das liberações de tempo, pois considera "[...] impossível introduzir de maneira uniforme nas empresas e para todo o pessoal a semana de 35 , ou 30, ou 25 horas em cinco dias. Mas é possível, em troca, introduzir para todo mundo uma duração anual de trabalho de 1400, ou 1200, ou 1000 horas por ano [...]" (idem, p. 190), em que o trabalhador continuaria recebendo salário regularmente.

Nessa perspectiva, o autor sugere que se cumpra o tempo de emprego de maneira mais concentrada, para que se tenha mais tempo disponí- 
vel - semanas, meses e anos - para o desenvolvimento de outras esferas da vida não diretamente ligadas ao emprego, como o desenvolvimento de um projeto, artístico ou técnico, individual, familiar ou comunitário; do contrário, a redução da jornada de trabalho como um tempo fracionado em algumas horas por dia apenas proporcionaria à pessoa alguns prazeres passivos, como consumir mais, executar tarefas domésticas, ir ao cinema e embriagar-se.

Grande parte desse argumento está fundada em uma critica à racionalidade econômica do mundo moderno, que atingiria, segundo o autor, todos os agentes envolvidos, desde o Estado e as empresas, até os trabalhadores e os sindicatos, as pessoas e os consumidores. Para Gorz, a racionalidade econômica não deixa lugar para a criatividade e a liberdade das pessoas, negando o uso do tempo que não tenha valor de troca e fim em si mesmo, pois esse não produz nem consome riquezas mercantis. "Ela exige o pleno emprego dos indivíduos empregados [...]" (idem, p. 116). Nesse sentido, o autor entende que o sindicalismo e o patronato seriam cúmplices históricos, uma vez que, para essas instituições, visando manterem seu poder, os indivíduos deveriam definir-se como "trabalhadores de tempo integral”, sendo tudo mais acessório. Para o patronato, "[...] o assalariado não era nada mais que sua força de trabalho; passada a soleira da fábrica, ele deixava de ser uma pessoa para tornar-se uma função. Aceitar empregar em tempo parcial mais gente do que o necessário era arriscar-se a estar em presença não de forças de trabalho, mas de pessoas, cada qual com sua individualidade e sua vida próprias, dificultando a disciplina, a coordenação, o mando" (ibidem).

Para o sindicato: "[...] era apenas como força de trabalho que os indivíduos deveriam ser defendidos e representados. [...] O aumento do tempo livre [...] só alcançou o primeiro plano das reivindicações sindicais sob a pressão de uma base, com freqüência externa aos aparelhos sindicais recalcitrantes. Isso porque o indivíduo, em seu tempo livre, deixa de ser um trabalhador; o desejo de tempo livre é precisamente o desejo de ser definido por outras atividades, valores e relações que não aquelas advindas do trabalho" (idem, p. 116-117).

Essa forte crítica está fundada na idéia de que, aumentando o tempo livre dos trabalhadores, os indivíduos poderiam subtrair-se à dominação dos patrões, mas também dos sindicalistas. A ampliação do "tempo livre" das pessoas torna-se, para Gorz, o aspecto mais positivo da redução da jornada de trabalho, permitindo alterar relações de poder e de dominação por meio do "livre desenvolvimento das aspirações sociais e individuais". Nessa perspectiva, está implícito que o pleno emprego, nos moldes do trabalho empobrecido, modelaria o modo de vida e a forma de consumo dos indivíduos em função da racionalidade econômica, o que seria pernicioso para a sociedade. Os trabalhadores, por sua vez, apenas descobririam os limites da racionalidade econômica à qual estão sujeitos quando suas vidas não fossem inteiramente preenchidas e suas mentes inteiramente ocupadas com o trabalho assalariado: quanto mais o trabalho fosse coercitivo, devido à intensidade e à duração, menos o trabalhador seria capaz de conceber sua vida com um fim em si mesma.

Florida (2004) sugere haver uma mudança radical em curso nas escolhas e atitudes da pessoa e descreve uma sociedade na qual o espírito criativo torna-se cada vez mais dominante. A partir de informações sobre transformações que vêm ocorrendo nos Estados Unidos há algumas décadas, o autor refere-se à constituição de uma nova classe econômica, creative class, formada por pessoas de escolaridade mais alta, que despendem mais tempo com educação, qualificação e profissão e que costumam, por isso, ter jornadas de trabalho mais longas que as outras camadas sociais, isto porque para "criar" é preciso um esforço continuado no trabalho. O fato é que essa classe criativa acaba tendo mais autonomia para "trabalhar mais". Embora suas jornadas contratuais de emprego possam reduzir-se, sua dedicação ao trabalho é maior.

Muito relevante ainda é demonstrar a vinculação entre a redução da jornada de trabalho e o desenvolvimento social e econômico, tomando como referencial explicativo as transformações históricas relevantes. Essa forma de pensar a questão, a partir de um movimento sócio-histórico, enfatiza o tratamento diferenciado que a matéria pode ter em distintas épocas e em contextos singulares, mesmo que centrada em um processo amplo de evolução das características da jornada de trabalho no mundo capitalista.

A discussão sobre a redução da jornada de trabalho surge com elementos diferentes em cada período histórico. Na segunda metade do século 
XIX, em várias partes do mundo eclodiram protestos dos trabalhadores pela redução da jornada de trabalho. Aquelas mobilizações buscavam dividir o dia em oito horas de trabalho, oito de descanso e oito de lazer. Como descreveram os pensadores da época, crianças, jovens e mulheres trabalhavam exaustivamente nas fábricas, em jornadas muito extensas, que podiam atingir mais de 15 horas por dia, o que causava muitas mortes e mutilação devido ao esgotamento físico.

Após atingir seu ápice no início da industrialização, a redução da jornada de trabalho, pela convergência de muitos fatores, acabou por diminuir nos últimos séculos. Entre o final do século XVII e meados do XIX, em algumas fábricas, as jornadas de trabalho para homens, mulheres e crianças atingiam mais de 80 horas semanais. Entre o início do século XIX até meados do século XX, a jornada de trabalho média reduziu-se de 67 para 48 ou 44 horas. Na virada para o século XXI, muitos países já possuem jornadas semanais de menos de 40 horas, e em algumas atividades laborais que demanda trabalho de elevada qualificação, as jornadas semanais chegam à média de 36 horas.

Com base nessas evidências, poder-se-ia afirmar que essa mudança foi resultado da introdução de inovações tecnológicas que ampliaram a capacidade produtiva e permitiram a execução do trabalho em menor tempo. Também seria correto afirmar que essa redução histórica da jornada de trabalho nas sociedades capitalistas decorreu da evolução das relações de trabalho e fora resultado dos movimentos operários e da ação sindical, que também se organizaram nesse contexto mais amplo.

Ambas as ponderações acima referidas são complementares e não mutuamente excludentes. A introdução de novas tecnologias no processo de produção contribuiu para o aumento da produtividade do trabalho, possibilitando o aumento da produção com redução da jornada de trabalho. Por outro lado, e ao mesmo tempo, as novas máquinas também passaram a exigir que os trabalhadores seguissem o ritmo das máquinas, o que foi verificado no período da racionalização do trabalho, da produção em massa, do taylorismo e do fordismo. Entretanto, posteriormente, com a introdução de tecnologias mais desenvolvidas, muito trabalho repetitivo foi substituído por equipamentos eletroeletrônicos, e novos empregos foram gerados em outros setores econômicos menos dependentes da automação, em geral o setor de serviços, onde se pode ou não demandar trabalho mais qualificado.

\section{FIGURA 1 - CURVA DA JORNADA DE TRABALHO E TRANSFORMAÇÕES HISTÓRICAS}

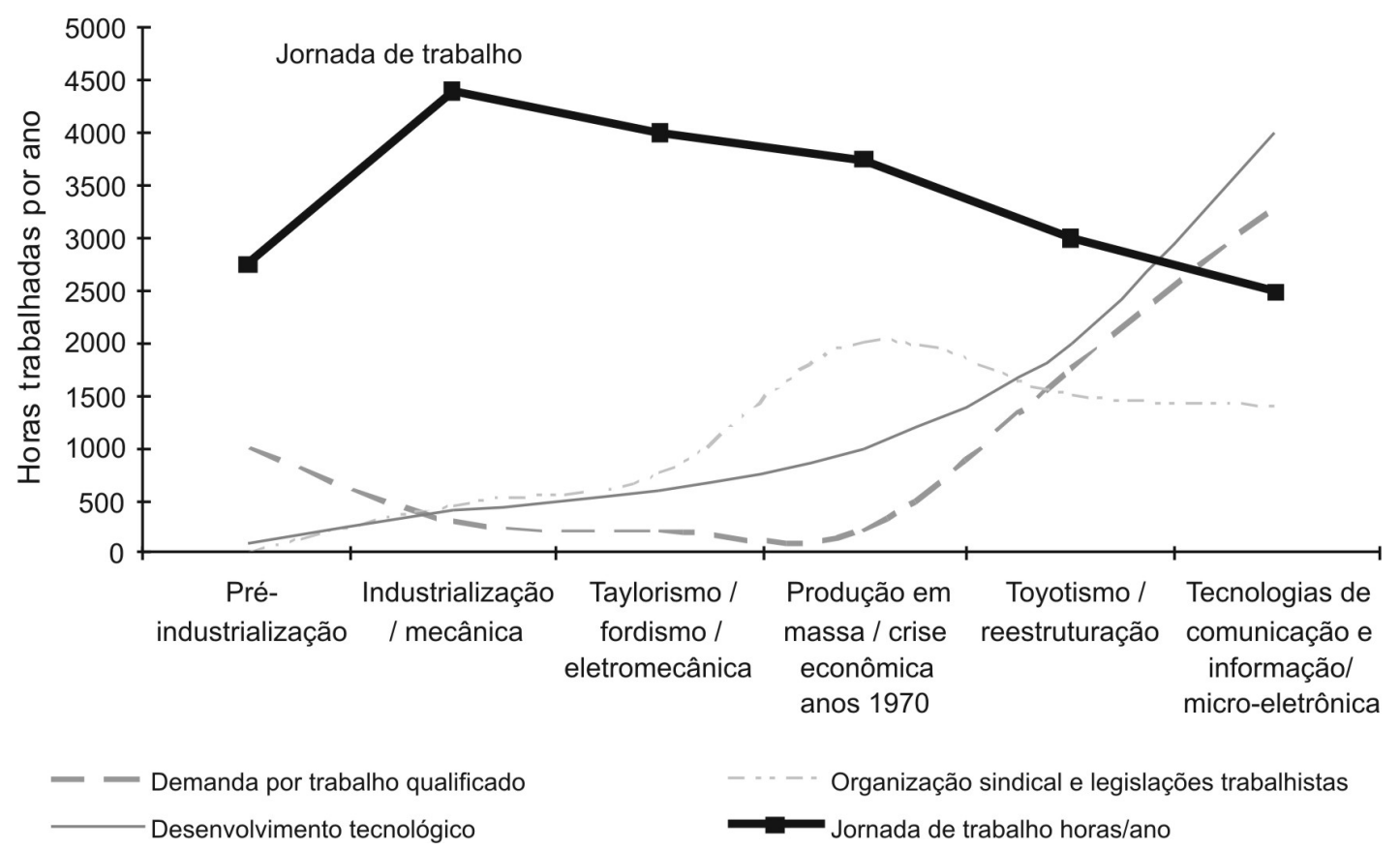

FONTE: adaptação livre e incrementada do modelo apresentado por Dal Rosso (2006, p. 308). 
A convergência de um conjunto de fatores pode estar relacionada a essa tendência, em especial destacam-se três: (1) o desenvolvimento histórico da organização dos trabalhadores e dos sindicatos e o da legislação trabalhista; (2) o desenvolvimento histórico da tecnologia aplicada à produção; (3) o desenvolvimento histórico da demanda por trabalho, que tende a ser uma demanda cada vez mais qualificada. Conforme explicado por Dal Rosso (2006), a duração da jornada de trabalho não é um dado fixo, imutável, no curso da história. A redução média da jornada de trabalho sempre envolveu transformações nas relações entre empregadores e trabalhadores, bem como transformações nas condições materiais, tecnológicas e culturais das sociedades. Para representar essa concepção, o autor apresenta um modelo gráfico para expressar as mudanças na duração do tempo de trabalho durante o capitalismo - em que fica representada a curva da jornada de trabalho e os movimentos históricos que tomaram lugar desde o surgimento do capitalismo até os dias de hoje, modelo que adaptamos a seguir. Essa formulação abstrata é adequada para analisar a tendência histórica de redução da jornada de trabalho no mundo ocidental, bem como consiste em um modelo válido para analisar o caso brasileiro.

Conforme a figura, os diferentes períodos de tempo possuem um valor mais do que apenas descritivo da tendência de redução da jornada de trabalho. Dal Rosso (idem) vai afirmar que, na Europa, a jornada de trabalho aumentou de duração do período posterior à Idade Média até a revolução industrial, atingindo seu ápice. Nesse período histórico, os trabalhadores teriam trabalhado mais de 14 horas diárias, o que teria deflagrado as primeiras mobilizações e revoltas, posteriormente chegando à organização dos trabalhadores e formulações de políticas trabalhistas.

Deve-se destacar a importância do grau de desenvolvimento de muitas sociedades e até mesmo das próprias atividades econômicas. Se tomássemos para análise, por exemplo, o caso de países em desenvolvimento, nos moldes dos anos 1960-1970, poder-se-ia observar o ápice da jornada de trabalho e seu pleno crescimento. Da mesma forma, se tomássemos para análise um setor econômico de ponta, poderíamos observar diferenciada tendência em relação a um setor tradicional ou de pouca intensidade tecnológica.
Situações diferentes também poderiam ser observadas em setores em que o movimento sindical fosse mais forte, ou em atividades laborais em que os trabalhadores fossem mais qualificados, devido ao seu maior poder de barganha.

Mais recentemente, haveria uma convergência de fatores que conduz à tendência da redução da jornada de trabalho, com especial destaque para o avanço tecnológico e o crescimento de ocupações mais complexas no mercado de trabalho, uma vez que a legislação trabalhista estaria ultrapassada e a atuação sindical parece ter perdido força. Se a organização sindical e as políticas trabalhistas foram forças fundamentais na redução da jornada de trabalho, após esta atingir seu ápice, os sindicatos e as legislações trabalhistas parecem "nadar contra a corrente", embora recentemente haja, ao que parece, maior preocupação desses atores com o acompanhamento das transformações econômico-sociais, uma vez que estariam revendo alguns de seus pressupostos.

A OIT publica periodicamente os IndicadoresChave do Mercado de Trabalho, conhecidos em sua sigla inglesa como KILM ("Key-Indicators of the Labour Market"). Esse documento põe em evidência diversas tendências relacionadas ao mundo do trabalho, entre os quais se destacam alguns dados sobre a jornada de trabalho. Os dados de 2006 indicam que em seis economias da Ásia o número de horas trabalhadas superou 2200 horas-ano. A república da Coréia do Norte lidera este grupo, seguida por Bangladesh, Sri Lanka, Hong Kong, China, Malásia e Tailândia. Em outro extremo estão os países da União Europeia como Alemanha, Bélgica, Dinamarca, França, Países Baixos e Suécia, onde se trabalham em média menos de 1600 horas-ano.

Essa diferença na quantidade de horas trabalhadas estaria vinculada ao grau de desenvolvimento econômico, tecnológico e social dos países e às políticas de desenvolvimento postas em prática. Na Ásia, a maior parte dos países tem se desenvolvido por meio da expansão da indústria tradicional, dependente de mão-de-obra em geral pouco qualificada, o que se verifica especialmente no caso da China. As exceções, no caso asiático, seriam Japão e Coréia do Sul que, como economias avançadas, podem dispor de trabalho em que a exploração da mão-de-obra não ocorre baseada no aumento do tamanho da jornada de trabalho, 
como seria o caso de indústrias tradicionais, intensivas em dispêndio de energia física.

Contudo, a redução da jornada de trabalho é diferente da idéia do trabalho em tempo parcial, que grande parte dos trabalhadores não têm visto como um tipo de contrato satisfatório. Segundo o KILM (2007, p. 12), na metade dos países da América Latina e do Caribe, pelo menos uma em cada oito pessoas empregadas trabalha em tempo parcial, porém queriam ter mais horas de trabalho. Os países com menor recorrência de empregos em tempo parcial são os da Europa Central e Oriental e os novos membros da União Européia. Já as economias mais avançadas da Europa Ocidental apresentariam crescimento significativo dos contratos parciais.

Dados da Relação Anual de Informações Sociais (Base RAIS) ${ }^{4}$, revelam que a média anual de horas contratadas no mercado de trabalho formal do Brasil foi de 1961 horas-ano, em 2008.

O tamanho da jornada de trabalho no Brasil é intermediário no contexto global anteriormente descrito e está aquém da evolução constatada nos países desenvolvidos, mas é menor do que nos países asiáticos. Contudo, essa média anual de horas contratadas varia segundo os grupos ocupacionais (Quadro 1). Os trabalhadores mais graduados trabalham, em média, menos horas anuais. As jornadas tendem a ser menores quanto maior a complexidade das atividades laborais. Os profissionais das ciências e das artes apresentam a menor média de horas anuais de trabalho, 1594 horas-ano, semelhante ao caso dos países mais desenvolvidos. As jornadas anuais são maiores para as categorias ocupacionais menos complexas, como trabalhadores dos serviços, vendedores, trabalhadores agropecuários, operários fabris e trabalhadores de manutenção e instalação; em todas essas últimas categorias citadas, as jornadas médias anuais superam 2028 horas-ano. Comparando com os profissionais das ciências e das artes, são cerca de 400 horas-ano a mais de trabalho.

QUADRO 1 - EVOLUÇÃO DA MÉDIA ANUAL DE HORAS CONTRATADAS SEGUNDO OS GRUPOS OCUPACIONAIS, BRASIL, 1994, 2000 E 2008

\begin{tabular}{|l|c|c|c|}
\hline CATEGORIA OCUPACIONAL & \multicolumn{3}{|c|}{ ANO } \\
\cline { 2 - 4 } & $\mathbf{1 9 9 4}$ & $\mathbf{2 0 0 0}$ & $\mathbf{2 0 0 8}$ \\
\hline Membros superiores do poder público e gestores de & 1772,64 & 1814,4 & 1942,56 \\
organizações $^{1}$ & 1556,16 & 1509,6 & 1594,56 \\
Profissionais das ciências e das artes, profissionais graduados & 1837,92 & 1850,4 & 1858,56 \\
Técnicos de Nível Médio & 1912,8 & 1937,76 & 1949,28 \\
Trabalhadores de serviços administrativos & 2017,2 & 2031,5 & 2028,96 \\
Trabalhadores dos serviços, vendedores do comércio & 2090,88 & 2097,6 & 2098,08 \\
Trabalhadores agropecuários, florestais e da pesca & 2077,44 & 2086,08 & 2086,56 \\
Trabalhadores da produção de bens e serviços industriais & 2075,52 & 2082,72 & 2072,64 \\
Trabalhadores da produção de bens e serviços industriais & 2049,6 & 2053,44 & 2061,6 \\
Trabalhadores em serviços de reparação e manutenção & 1940,64 & 1948,32 & 1960,8 \\
\hline Brasil (geral)
\end{tabular}

FONTE: Ministério do Trabalho e Emprego; base estatística da RAIS.

NOTA: 1. Magistrados, procuradores, delegados, dirigentes de organizações privadas, gerentes, diretores e cargos de gestão em geral.

\footnotetext{
4 A Relação Anual de Informações Sociais, instituída em 1975, fornece informações estatísticas sobre o mercado de trabalho formal no Brasil, funcionando em conjunto com o Cadastro Geral de Empregados e Desempregados (Caged), criado em 1965, que instituiu o registro permanente de admissões e dispensa de empregados; são mantidos pelo Ministério do Trabalho e Emprego. As bases estatísticas podem ser conferidas em MTE (2010), mediante cadastro como pesquisador
}

Essa média anual de horas contratadas vem em evolução desde 1994. Diferente do caso registrado nos países mais desenvolvidos, no Brasil há uma leve tendência de aumento da jornada anual, entre 1994 e 2008. Essa situação reproduz-se em praticamente todas as categorias ocupacionais, aumentando inclusive no caso dos profissionais das ciências e das artes, para os quais a média anual de horas contratadas passa de 1556 horas- 
ano, em 1994, para 1594 horas-ano, em 2008. Somando-se a isso o fato do grande crescimento do número de empregos no mercado de trabalho formal, pode-se afirmar que o contexto de crescimento econômico que se passa no Brasil registra certa falta de mão-de-obra, condição que justifica esse aumento das horas contratadas nas diversas classes ocupacionais, mesmo com o maior volume do mercado de trabalho formal.

Entre as afirmações categóricas proferidas pelos teóricos, o debate público em geral, o discurso sindical, a simpatia política e as evidências empíricas, parece que ficar com as últimas é o caminho mais acertado para pensar-se a questão. Não se trata de desmerecer alguns dos elementos que ficam em destaque em cada uma dessas perspectivas, mas compreender singularidades específicas acerca da redução da jornada de trabalho. Contudo, parece fundamental pensar a questão considerando-a no contexto histórico do desenvolvimento socioeconômico geral e singular.

\section{CARACTERÍSTICAS DA JORNADA DE TRABALHO NOBRASIL}

Dal Rosso (2006) descreveu alguns elementos históricos importantes do contexto de redução da jornada de trabalho no Brasil. Houve duas mudanças no tamanho da jornada de trabalho determinadas pela legislação, uma na Constituição de 1934 e outra na de 1988. Na Constituição de 1934 foi estabelecida a jornada de trabalho de 48 horas semanais (oito horas diárias).

As primeiras indústrias brasileiras foram instaladas no século XIX e não teria tardado a emergir os primeiros movimentos reivindicatórios pela redução da jornada. As greves de 1907, 1912 e 1917 teriam conseguido algumas vitórias, após incluírem em suas pautas os temas da duração e da intensidade do trabalho. Em 1932, o movimento operário teria obtido a fixação legal da duração da jornada de trabalho em oito horas diárias por seis dias da semana, acrescidas da possibilidade de complementação com mais duas horas-extras ao dia. A partir de 1985, os movimentos grevistas mais combativos estabeleceram acordos separados por empresas e conseguiram reduzir as jornadas de trabalho. Como afirmam Gonzaga, Menezes Filho e Camargo (2003), em 1988, quando a jornada de trabalho de 44 horas semanais foi oficializada pela Constituição, a maior parte dos empregos já tinha jornadas menores que 48 horas, seguindo uma tendência histórica.

O artigo sétimo da Constituição de 1988 regulamentou a jornada de trabalho de 44 horas semanais e oito horas diárias, em 5,5 dias por semana; estabeleceu que o número máximo de horas-extras diárias não pode exceder duas horas, e a remuneração das horas-extras deve ser de no mínimo $150 \%$ do valor da hora normal. Segundo a Constituição, jornadas menores e flexibilização da jornada por períodos superiores a uma semana só podem ser efetivadas por negociação individual ou coletiva (BRASIL, 1988).

Dal Rosso (1998) ao fazer uma análise mais pormenorizada do caso brasileiro quando da redução da jornada de trabalho de 48 para 44 horas, quantificou o efeito na criação de novos postos de trabalho. A redução de $8,33 \%$ da jornada de trabalho legal resultou na criação de, aproximadamente, apenas $1 \%$ de novos postos de trabalho. Segundo o autor, a diferença de 7,33\% explica-se pelas estratégias adotadas pelas empresas para contrabalançar a redução da jornada legal. A principal estratégia teria sido o aumento da utilização de horas-extras, que saltou de $24 \%$ nos meses anteriores à promulgação da Constituição para $41 \%$ nos meses posteriores.

O caso do mercado de trabalho formal do Brasil é diferente do latino-americano, em razão de sua economia que mescla atividades laborais bastante tradicionais com outras de ponta - mais desenvolvidas. Não se pode, contudo, negar que haja elevada informalidade no mercado de trabalho no Brasil, embora esse seja menor em relação a outros países da região. No âmbito do mercado de trabalho informal, é difícil conhecer mais afundo a questão das jornadas de trabalho, que tendem a ser muito extensas, pois não são reguladas pela legislação. Todavia, muitas informações estão disponíveis sobre o tamanho da jornada de trabalho no mercado de trabalho formal brasileiro. Tratar de algumas características desse mercado de trabalho ajuda-nos a revelar importantes aspectos sobre a realidade do mercado de trabalho formal no Brasil, especialmente no que diz respeito ao tamanho da jornada de trabalho e inter-relações com outras variáveis. Também se deve destacar o grande crescimento do número de empregos formais nos últimos anos, o que encorpou muito o mercado de trabalho no Brasil. 
QUADRO 2 - EVOLUÇÃO DA DISTRIBUIÇÃO DO NÚMERO DE EMPREGOS FORMAIS POR TAMANHO DA JORNADA DE TRABALHO, BRASIL, 1994, 2000 E 2008

\begin{tabular}{|l|c|c|c|c|c|c|}
\hline \multirow{2}{*}{ Jornada } & \multicolumn{2}{|c|}{1994} & \multicolumn{2}{c|}{ 2000 } & \multicolumn{2}{c|}{$\mathbf{2 0 0 8}$} \\
\cline { 2 - 7 } & Número & $\%$ & Número & $\%$ & Número & $\%$ \\
\hline Até 20 h & 784116 & 3,31 & 919732 & 3.51 & 1390337 & 3,53 \\
$21-30 \mathrm{~h}$ & 2142437 & 9,05 & 2297507 & 8,76 & 2770476 & 7,02 \\
$31-40 \mathrm{~h}$ & 5650688 & 23,88 & 5554031 & 21,18 & 7857354 & 19,92 \\
$41-44 \mathrm{~h}$ & 14979030 & 63,29 & 17457359 & 66,56 & 27423399 & 69,53 \\
Mais de 45h & 16497 & 0,07 & 0 & - & 0 & - \\
Ignorado & 94473 & 0,40 & 0 & - & 0 & - \\
Total & 23667241 & 100,0 & 26228629 & 100,0 & 39441566 & 100,0 \\
\hline
\end{tabular}

FONTE: Ministério do Trabalho e Emprego; Base RAIS.

Dados da Base Rais, indicam uma concentração de empregos com jornada entre 41 e 44 horas, que representam $70 \%$ dos empregos, em 2008; apenas 3,5\% dos empregados do mercado de trabalho formal trabalham em tempo parcial (até 20 horas) (Quadro 2). Também se destaca significativa concentração de empregos com jornadas entre 31 e 40 horas semanais, que foi de 20\% (Quadro 2), mas que estão, em geral, ocupados por trabalhadores com maior grau de instrução (Quadro 3). Entre 1994 e 2008, houve grande expansão do mercado de trabalho formal, com um crescimento de quase 16 milhões de empregos formais. No período, houve crescimento na participação de empregos com jornadas entre 41 e 44 horas, que passou de $63 \%$ para $70 \%$. Destaca-se, ainda, que houve redução do contingente de empregos com jornada entre 31 e 40 horas, de 24\% para 20\% (Quadro 2).
A partir do Quadro 3, podemos observar que, em 2008, os empregos com jornada de trabalho mais longa, entre 41 e 44 horas, eram ocupados em sua maior parte por trabalhadores com menor grau de instrução. Os trabalhadores com até o Ensino Médio incompleto, aqueles geralmente alocados em atividades laborais repetitivas e rotineiras, ou em serviços domésticos e no meio rural, estavam empregados no mercado de trabalho formal sempre em patamares maiores que $80 \%$, situação que se repete nos anos anteriores, 1994 e 2000, caracterizando-se uma tendência. A partir do Ensino Médio completo, esse número cai em $9 \%$ ( $72 \%$ dos empregados com Ensino Médio no mercado de trabalho formal do Brasil têm jornadas de 40 a 44 horas); caindo mais $12 \%$ quando chega ao Ensino Superior incompleto (60\% dos empregados com Ensino Superior incompleto no mercado de trabalho formal do Brasil têm jornadas de 40 a 44 horas).

QUADRO 3 -PROPORÇÃO DO NÚMERO DE EMPREGOS POR TAMANHO DA JORNADADE TRABALHO E SEGUNDO O GRAU DE INSTRUCÃO DOS TRABALHADORES, BRASIL, 1994, 2000 E 2008

\begin{tabular}{|c|c|c|c|c|c|c|c|c|c|}
\hline \multirow[b]{2}{*}{ Jornada (horas) } & \multicolumn{3}{|c|}{1994} & \multicolumn{3}{|c|}{2000} & \multicolumn{3}{|c|}{2008} \\
\hline & $21-30$ & $31-40$ & $41-44$ & $21-30$ & $31-40$ & $41-44$ & $21-30$ & $31-40$ & $41-44$ \\
\hline Doutorado & $\mathrm{NI}$ & $\mathrm{NI}$ & $\mathrm{NI}$ & $\mathrm{NI}$ & $\mathrm{NI}$ & $\mathrm{NI}$ & 9,18 & 54,35 & 13,08 \\
\hline Mestrado & $\mathrm{NI}$ & $\mathrm{NI}$ & $\mathrm{NI}$ & $\mathrm{NI}$ & $\mathrm{NI}$ & $\mathrm{NI}$ & 19,39 & 25,30 & 24,06 \\
\hline Superior completo & 15,91 & 48,92 & 21,47 & 20,24 & 40,04 & 26,34 & 18,32 & 36,57 & 30,94 \\
\hline Sup. Incompleto & 16,79 & 35,15 & 43,40 & 14,69 & 35,00 & 45,67 & 9,49 & 27,59 & 60,21 \\
\hline E. Médio compl. & 16,52 & 35,42 & 43,29 & 10,83 & 27,51 & 58,21 & 5,54 & 20,75 & 72,09 \\
\hline E. Médio incomp. & 7,30 & 18,51 & 72,15 & 5,74 & 14,84 & 77,82 & 4,52 & 11,90 & 81,37 \\
\hline $9^{\mathrm{a}}$ série comp. & 6,16 & 22,75 & 69,54 & 5,39 & 15,52 & 77,16 & 4,49 & 12,91 & 81,73 \\
\hline 6 a $9^{a}$ série incom. & 4,46 & 12,64 & 81,45 & 3,81 & 10,86 & 84,34 & 2,82 & 10,31 & 85,98 \\
\hline 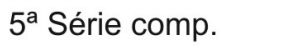 & 3,63 & 13,61 & 81,40 & 4,51 & 13,82 & 80,66 & 3,29 & 11,58 & 84,22 \\
\hline Até $5^{a}$ série incom. & 5,27 & 12,94 & 79,21 & 6,44 & 14,54 & 77,44 & 3,18 & 13,54 & 82,31 \\
\hline Analfabetos & 13,23 & 17,74 & 65,47 & 10,09 & 12,61 & 75,18 & 2,08 & 10,21 & 86,69 \\
\hline
\end{tabular}

FONTE: Ministério do Trabalho e Emprego; Base RAIS.

NOTA: Não foi contabilizada a participação das faixas de jornadas menores que 20 horas, o que pode ser obtido subtraindo a soma das categorias de 100 . 
A escolaridade está diretamente vinculada ao tamanho da jornada semanal contratual dos trabalhadores. Os dados do mercado de trabalho formal brasileiro reforçam a hipótese de que, com a elevação do grau de instrução dos empregados, que se segue da demanda por trabalho mais qualificado, diminui o tamanho da jornada, sem chegar a predominar o grupo das atividades em tempo parcial (menos de 30 horas) para os trabalhadores mais instruídos. Os trabalhadores mais escolarizados, com Ensino Superior completo, Mestrado e Doutorado têm baixa participação nos empregos com jornadas mais longas (41 a 44 horas), respectivamente, $31 \%, 24 \%$ e $13 \%$, em 2008 .

Quando observamos os dados dos empregos com jornada de trabalho entre 31 e 40 horas, a relação constatada é quase inversa à dos trabalhadores menos escolarizados, visto que se pode constatar maior concentração de trabalhadores mais escolarizados: $57 \%$ dos doutores, $25 \%$ dos mestres e $38 \%$ dos graduados estão em empregos com jornada mais curta ( 31 a 40 horas); a participação dos trabalhadores com Ensino Médio incompleto e menos, nesta faixa, não supera $15 \%$.

QUADRO 4 - REMUNERAÇÃO MÉDIA (EM R\$) POR INSTRUÇÃO DO EMPREGADO E TAMANHO DA JORNADA DE TRABALHO (EM HORAS SEMANAIS) (BRASIL, 2008)

\begin{tabular}{|l|c|c|c|c|c|}
\hline $\begin{array}{l}\text { Remuneração média por } \\
\text { instrução }\end{array}$ & $\begin{array}{c}\text { Tempo } \\
\text { parcial }^{1}\end{array}$ & $\mathbf{2 1} \mathbf{a} \mathbf{3 0} \mathbf{~}$ & $\mathbf{3 1} \mathbf{a} \mathbf{4 0} \mathbf{~}$ & $\mathbf{4 1} \mathbf{~ a ~ 4 4 ~ \mathbf { ~ }}$ & Total \\
\hline Doutorado & 3188,78 & 5026,24 & 8811,77 & 5589,07 & 6727,39 \\
Mestrado & 2436,35 & 3330,21 & 6670,41 & 4532,50 & 4185,19 \\
Superior completo & 1901,61 & 2534,81 & 4604,85 & 3374,08 & 3461,82 \\
Superior incompleto & 1053,78 & 1813,13 & 2212,02 & 1635,30 & 1795,55 \\
Ensino Médio completo & 810,32 & 1460,18 & 1653,28 & 1006,97 & 1163,01 \\
Até EnsinoFundamental & 460,5 & 850,64 & 1254,74 & 813,96 & 864,16 \\
Total & 1506,95 & 1797,07 & 2463,72 & 1102,47 & 1436,70 \\
\hline
\end{tabular}

FONTE: Ministério do Trabalho e Emprego; Base estatística da Rais.

NOTA: 1. Jornada de até 20 horas semanais.

Um fato curioso sobre esse último aspecto refere-se à observação de que, quanto maior a formação do trabalhador, maior acaba sendo também a participação de empregados contratados em tempo parcial, especialmente no caso daqueles com mestrado $(31,25 \%)$ e doutorado $(23,19 \%)$. Esse parece ser um caso vinculado ao caso das universidades privadas, centros de pesquisa, consultorias, que tendem em muitos casos a contratar por tempo mais reduzido. Deve-se destacar ainda que há um contingente significativo de servidores públicos privilegiados, com jornadas que variam entre 36 e 40 horas. Se, por um lado, esse fato demonstra que os empregados mais qualificados são contratados por menor tempo, flexibilizando a prestação de serviço, também significa, por outro lado, que existe um maior valor da hora de trabalho, o que encarece ou não justifica a contratação dos profissionais em jornadas completas, por parte dos empregadores. As remunerações médias são maiores para os trabalhadores com jornadas entre 31 e 40 horas (Quadro 4), mas este dado parece refletir o caso do funcionalismo público. Os empregos com jornadas de 41 a 44 horas apresentam remuneração média menor em todas as faixas de instrução. Uma possível medida de redução da jornada recairia sobre empregos que têm remuneração menor que aqueles em que a jornada já é reduzida. A instrução é o fator mais evidente no quesito remuneração média, não sendo determinante o tamanho da jornada. 
QUADRO 5 - TEMPO MÉDIO DE CONTRATAÇÃO (HORAS SEMANAIS) E REMUNERAÇÃO MÉDIA POR GRAU DE INSTRUÇÃO (BRASIL, 1994, 2000 E 2008)

\begin{tabular}{|c|c|c|c|c|c|c|}
\hline \multirow[b]{2}{*}{ Instrução } & \multicolumn{3}{|c|}{$\begin{array}{l}\text { Tempo médio de contratação } \\
\text { (horas) }\end{array}$} & \multicolumn{3}{|c|}{$\begin{array}{l}\text { Remuneração } \\
\text { Média }(\mathbf{R} \$)^{*}\end{array}$} \\
\hline & 1994 & 2000 & 2008 & 1994 & 2000 & 2008 \\
\hline Doutorado & $\mathrm{NI}$ & $\mathrm{NI}$ & 32,01 & $\mathrm{NI}$ & $\mathrm{NI}$ & 6727,15 \\
\hline Mestrado & $\mathrm{NI}$ & $\mathrm{NI}$ & 28,61 & $\mathrm{NI}$ & $\mathrm{NI}$ & 4183,20 \\
\hline Superior completo & 35,44 & 35,12 & 35,31 & 1040,90 & 2015,85 & 3461,10 \\
\hline Superior incompleto & 38,52 & 38,75 & 40,35 & 804,30 & 1313,70 & 1801,10 \\
\hline Ensino Médio completo & 38,61 & 40,01 & 41,55 & 488,60 & 761,04 & 1162,00 \\
\hline Ensino Médio incompleto & 41,36 & 41,89 & 42,01 & 371,00 & 546,62 & 871,50 \\
\hline $9^{a}$ série completo & 41,53 & 41,79 & 42,38 & 324,80 & 525,48 & 917,15 \\
\hline 6 a $9^{a}$ série incompleto & 42,25 & 42,55 & 42,74 & 289,10 & 453,00 & 842,45 \\
\hline $5^{\text {a }}$ série completo & 42,36 & 42,31 & 42,61 & 284,20 & 456,02 & 838,30 \\
\hline Até $5^{\mathrm{a}}$ série incompleto & 41,84 & 41,84 & 42,56 & 248,50 & 404,68 & 771,90 \\
\hline Analfabetos & 40,29 & 41,09 & 42,85 & 270,90 & 413,74 & 593,45 \\
\hline
\end{tabular}

FONTE: Ministério do Trabalho e Emprego; Base RAIS.

NOTA: Remuneração média em valor nominal corrente no ano referido, sem reajuste inflacionário.

Considerando o tempo médio de contratação por faixa de instrução dos trabalhadores, pode-se perceber que o tamanho médio da jornada semanal não aumenta apenas para os trabalhadores com Ensino Superior (Quadro 5), que em 1994, 2000 e 2008 foi de 35 horas semanais. Em todos os graus de instrução inferiores ao Superior, houve aumento na média de horas contratadas. $O$ fato é que, mesmo com o aumento do volume do mercado de trabalho brasileiro, os contratos de trabalho estão maiores, especialmente para as categorias de menor instrução. Os trabalhadores com até Ensino Médio incompleto trabalham em média mais do que 42 horas semanais, em 2008. Os trabalhadores com Ensino Médio completo trabalham, em média, 41,55 horas semanais. Os trabalhadores com Ensino Superior completo trabalham em média 40,35 horas semanais. Até o Ensino Superior incompleto, as jornadas médias semanais diminuem pouco, embora seja uma redução constante. Já os trabalhadores com Ensino Superior completo trabalham em média 35,31 horas semanais; os com mestrado 28,61 e os com doutorado, trinta e duas.

\section{CONCLUSÕES}

Buscou-se levantar um conjunto de aspectos teóricos e de evidências históricas e empíricas que possam subsidiar um debate promissor sobre a questão da redução da jornada de trabalho, em especial atentando para o diálogo público que se promete para o Brasil, nos próximos anos. É importante destacar que não se considera a redução da jornada de trabalho como um processo negativo, mas que é preciso estabelecer algumas ponderações. Entre os pontos mais relevantes, destaca-se o fato evidente de que a redução da jornada de trabalho é um processo histórico vinculado ao desenvolvimento econômico, às mudanças sociais e culturais e à natureza das atividades laborais. $\mathrm{O}$ que se defende é que a redução da jornada de trabalho precisa ser discutida primeiramente pelo viés da qualidade dos empregos, deixando a questão da quantidade dos empregos em segundo plano, especialmente considerando o contexto recente de ampla geração de empregos formais no Brasil. Há indícios de que uma medida política, determinada de cima para baixo, pode acarretar, no longo prazo, um processo contrário aos objetivos daqueles que a defendem deliberadamente. Parece inoportuno reduzir a jornada de trabalho sem valorizar a remuneração e as demais condições de emprego e sem considerar a natureza das atividades laborais. Porém, essa valorização depende de aspectos que não dizem respeito unicamente à legislação trabalhista, ao poder de barganha dos trabalhadores ou à ação sindical, mas também a elementos próprios ao mercado de trabalho. Constatou-se, por exemplo, que as categorias ocupacionais, a instrução e a qualificação são fa- 
tores decisivos para melhorar a remuneração e as condições de emprego, além de ter efeito direto sobre o menor tamanho da jornada de trabalho.

Mais que estabelecer objetivos acerca da quantidade de emprego, o debate sobre a redução da jornada de trabalho precisa estar focado em objetivos referentes à sua qualidade. O Dieese (2007) sugere, em uma de suas últimas publicações, que reduzir a jornada de trabalho produzirá empregos de qualidade. Sem estar relacionada a um conjunto de outros fatores, essa idéia seria equivocada e de pouco embasamento, por partir do pressuposto que, trabalhando quatro horas semanais a menos, os trabalhadores já teriam um "emprego melhor". A qualidade do emprego não se expressa essencialmente pelo tamanho da jornada de trabalho, pelo contrário, talvez seja um dos indicadores de menor importância nessa matéria. A qualidade do emprego hoje perpassa a possibilidade de desenvolvimento não apenas profissional, mas das aspirações sociais e individuais. É o trabalho rico, com maior volume de conteúdo, que tem maior valor no mercado. $\mathrm{O}$ trabalho empobrecido em conteúdo, baseado em tarefas simples e rotineiras, tem baixo valor no mercado de trabalho, e reduzir a jornada destes postos acarretará em menor remuneração e manutenção de sua baixa qualidade.

É preciso estar atento a uma falácia: a defesa da idéia de que, com a redução da jornada de trabalho, "os trabalhadores trabalharam menos e ganharão mais". O debate sobre a redução da jorna- da de trabalho é urgente. Contudo, é simplório pensar que essa medida, de maneira isolada e descontextualizada, por si só resolveria problemas como o desemprego, os baixos salários e a precarização do trabalho. Dependendo da forma como for proposta, a redução da jornada pode potencializar a precarização do emprego e enfraquecer ainda mais a proteção social dos trabalhadores, além do próprio sindicalismo. Reduzir a jornada de trabalho está no centro de uma série de mudanças na infraestrutura social, mas que exige também mudanças ideológicas e culturais.

Muitas questões precisam ser examinadas, repensadas e redefinidas, o que passa pela prática e o conteúdo do próprio sindicalismo. Não é suficiente criar mais empregos. Parece ser preciso pensar em criar mais e melhores empregos. Que tipo de empregos seria criado com uma política de redução da jornada que fosse precipitada, ou politicamente imposta? Ampliar o volume de trabalho rotineiro e repetitivo, que requer mão-de-obra desqualificada e socialmente dependente, especialmente do Estado, que gera salários baixos e indivíduos desmotivados, não resolveria os problemas mais profundos da realidade social, poderia antes agravá-los. Considerando a importância do discurso sindical e da simpatia política por este, a questão que envolve a redução da jornada de trabalho perpassa o sentido teórico que essa prática assume. Todavia, as evidências empíricas parecem ser subsídios decisivos para complementar essa discussão, por isso, não podem ser subestimadas pelo debate público.

Daniel Gustavo Mocelin (dmocelin@terra.com.br ) é Doutorando em Sociologia pela Universidade Federal do Rio Grande do Sul (Ufrgs).

\section{REFERÊNCIAS BIBLIOGRÁFICAS}

ARENDT, H. 2005. A condição humana. $10^{\mathrm{a}}$ ed. Rio de Janeiro: Forense.

AZNAR, G. 1995. Trabalhar menos para trabalharem todos. São Paulo: Página Aberta.

BESCOND, D.; CHÂTAIGNIER, A. \& MEHRAN, F. 2003. Seven Indicators to Measure Decent Work: an International Comparison. International Labour Review, Hoboken (NJ), v. 142, n. 2, p. 179-211, June.
BOSCH, G. 1999. Working Time: Tendencies and Emerging Issues. International Labour Review, Hoboken (NJ), v. 138, n. 2, p. 131-149, June.

BOSCH, G. \& LEHNDORFF, S. 2001. WorkingTime Reduction and Employment: Experiences in Europe and Economic Policy Recommendations. Cambridge Journal of Economics, v. 25, n. 2, p. 209-243. Disponível em: http://lmps.gofor.de/cambridgeworkingTimereduction.pdf. Acesso em: 5.jan.2010. 
CALVETE, C. S. 2003. A redução da jornada de trabalho como solução do desemprego: o mito de Sísifo ou Prometeu? Civitas, Porto Alegre, v. 3, n. 2, p. 417-433, jul.-dez. Disponível em: http://revistaseletronicas.pucrs.br/ojs/ index.php/civitas/article/viewFile/128/123. Acesso em: 5.jan.2010.

2006. Redução da jornada de trabalho: uma análise econômica para o Brasil. Campinas Tese (Doutorado em Economia). Universidade Estadual de Campinas.

CARNEIRO, T. L. \& FERREIRA, M. C. 2007. Redução de jornada melhora a qualidade de vida no trabalho? A experiência de uma organização pública brasileira. Revista Psicologia: Organizações e Trabalho, Brasília, v. 7, n. 1, p. 131-157. Disponível em: http:// pepsic.homolog.bvsalud.org/pdf/rpot/v7n1/ v7n1a07.pdf . Acesso em: 5.jan.2010.

CASTEL, R. 1998. As metamorfoses da questão social: uma crônica do salário. Petrópolis: Vozes.

2005. A insegurança social. O que é ser protegido? Petrópolis: Vozes.

DAL ROSSO, S. 1998. O debate sobre a redução da jornada de trabalho. São Paulo: Associação Brasileira de Estudos do Trabalho.

2002. Working Time in Brazil: Past Experience and Recent Changes. Time \& Society, Sunnyvale (CA), v. 11, n. 1, p. 67-86.

2006. Tempo de trabalho. In: CATTANI, A. D. \& HOLZMANN, L. Dicionário de trabalho e tecnologia. Porto Alegre: UFRGS.

ESTRADE, M.; MÉDA, D. \& ORAIN, R. 2001. Les effets de la réduction du temps de travail sur les modes de vie: qu'en pensent les salariés um an aprés? Premières Informations, Premières Synthèses, Paris, n. 21.1, p. 1-4, mai. Disponível em: http://www.cee-recherche.fr/ fr/fiches_chercheurs/texte_pdf/meda/ rttps.pdf. Acesso em: 5.jan.2010.

FLORIDA, R. 2004. The Rise of the Creative Class: and How It's Transforming Work, Leisure, Community. New York: Basic.

GHAI, D. 2003. Decent Work: Concept and Indicators. International Labour Review,
Hoboken, v. 142, n. 2, p. 113-145. Disponível em: http://www.ilo.org/public/english/revue/ download/pdf/ghai.pdf. Acesso em: 5.jan.2010.

GONZAGA, G. M.; MENEZES FILHO, N. A. \& CAMARGO, J. M. 2003. Os efeitos da redução da jornada de trabalho de 48 para 44 horas semanais em 1988. Revista Brasileira de Economia, Rio de Janeiro, v. 57, n. 2, p. 369-400. Disponível em: http://www.scielo.br/pdf/rbe/ v57n2/a03v57n2.pdf. Acesso em: 5.jan.2010.

GORZ, A. 2003. Metamorfoses do trabalho: crítica da razão econômica. São Paulo: Annablume.

2004. Misérias do presente, riqueza do possivel. São Paulo: Annablume.

KARSTEN, L. \& LEOPOLD, J. 2003. Time and Management: the Need for Hour Management. Personnel Review, Bingley, v. 32, n. 4, p. 405421.

MÉDA, D. 1999. O trabalho: um valor em vias de extinção. Lisboa: Fim de Século.

OFFE, C. 1994. Capitalismo desorganizado. São Paulo: Brasiliense.

1997. Desemprego, sindicato e inovação na política social. Ensaios FEE, Porto Alegre, v. 18, p. 181-91. Disponível em: http:// revistas.fee.tche.br/index.php/ensaios/article/ viewFile/1888/2262. Acesso em: 5.jan.2010.

PÉLISSE，J. 2004. From Negotiation to Implementation: a Study of the Reduction of Working Time in France (1998-2000). Time \& Society, Sunnyvale, v. 13, n. 2-3, p. 221224.

SINGE, I. \& CROUCHER, R. 2003. The Management of Trust-Based Working Time in Germany. Personnel Review, Bingley, v. 32, n. 4 , p. 492-509.

TIETZE, S. \& MUSSON, G. 2002. When "Work" Meets "Home": Temporal Flexibility as Lived Experience. Time \& Society, Sunnyvale, v. 11, n. 2-3, p. 315-334.

WALSH, J. \& DEERY, S. 1999. Understanding the Peripheral Workforce: Evidence Form the Service Sector. Human Resource Management Journal, Hoboken, v. 9, n. 2, p. 50-63, Aug. 


\section{OUTRAS FONTES}

BRASIL. 1988. Constituição da República Federativa do Brasil de 5 de outubro de 1988. Brasília: Senado Federal.

DEPARTAMENTO INTERSINDICAL DE ESTATÍSTICA E ESTUDOS SOCIOECONÔMICOS (DIEESE). 2006. Redução da jornada de trabalho no Brasil. Nota técnica, São Paulo, n. 16, p. 1-11, mar. Disponível em: http:/ /www.fenajufe.org.br/encontro6horas/arquivos/notatec 16ReducaoDaJornada\%20\%20Dieese.pdf. Acesso em: 30.jan.2010.

2007. Reduzir a jornada de trabalho é gerar empregos de qualidade. Nota técnica, São
Paulo, n. 57, p. 1-10. Disponível em: http:// www.fenajufe.org.br/encontro6horas/arquivos/notatec57JornadaTrabalho\%20dieese.pdf. Acesso em: 5.jan.2010. Acesso em: 5.jan.2010.

MINISTÉRIO DO TRABALHO E EMPREGO (MTE). 2010. Cadastro Geral de Empregados e Desempregados (Caged). Disponível em: http:/ /portal.mte.gov.br/caged/. Acesso em: 5.jan.2010.

ORGANIZAÇÃOINTERNACIONAL DO TRABALHO (OIT). 2007. Los Indicadores Clave del Mercado de Trabajo (KILM). Genebra: Organização Internacional do Trabalho. 

DISCOURSE, THEORY AND REALITY

\section{Daniel Gustavo Mocelin}

The goal of this essay is to critically examine the topic of work day reduction, expounding some of the important theoretical and empirical dimensions that are often excluded from public debate on the matter. Analyzing some of the characteristics of workers' contracts within the Brazilian labor market, we demonstrate that there is considerable distance between discourse and academic readings of the issue and its reality. The reduction of the work day is a multi-faceted theme that characterizes a complex and polysemic debate, stirring the interest of a variety of social agents who are interested in the matter but whom maintain different conceptions of it, given the heterogeneity of the values that are at stake. We argue that the social implications of a political measure reducing the work day cannot be predicted. Nonetheless, such a reduction is a historic tendency, linked to socio-economic development. There are marked differences between trade union discourse, political sympathies, theoretical assertions and empirical evidence on the matter This essay looks at two main dimensions of the topic: quality and quantity of employment. When examined from the quantitative side, the issue of job creation comes to the fore, in the interests of minimizing the effects of unemployment. When the focus turns to the qualitative side, what is at stake is the issue of the relationship of work activities to wealth and outputs, of providing real improvements in work conditions and worker's quality of life.

KEYWORDS: Work Day Reduction; Employment; Job Quality. 


\section{Daniel Gustavo Mocelin}

Le but de cet article est d'examiner le thème de la réduction de la journée de travail de façon critique, en exposant certaines dimensions théoriques et empiriques importantes qui sont normalement exclues du débat public sur la question. En analysant quelques caractéristiques sur le temps d'embauche des travailleurs dans le marché de travail brésilien, on démontre qu'il existe une grande distance entre le discours, la lecture académique sur la question et la réalité. La réduction de la journée de travail est un thème avec des multiples facettes, ce qui caractérise un débat complexe et polémique, favorisant ainsi l'intérêt de plusieurs agents sociaux sur cette question, mais qui possèdent différentes conceptions autour du débat, en raison de l'hétérogénéité des valeurs en jeu. Dans l'article, on soutient que les implications sociales d'une mesure politique de réduction de la journée de travail ne peuvent pas être prévues. Toutefois, on comprend que cette réduction est une tendance historique, liée au développement social et économique. Il y a des différences frappantes entre le discours de syndicat, la sympathie politique par la mesure, les affirmations théoriques et les évidences empiriques sur la thématique. L'article aborde le thème avec deux dimensions principales: quantité et qualité de l'emploi. Quand abordé par la perspective de la quantité de l'emploi, il implique la question de la création d'emplois, avec l'objectif de réduire au minimum les effets du chômage. Quand abordé par la perspective de la qualité de l'emploi, il implique la question de la richesse des activités de travail et la meilleure productivité, en fournissant une réelle amélioration dans les conditions de travail et dans la qualité de vie des travailleurs.

MOTS-CLES: réduction de la journée de travail; emploi; qualité de l'emploi. 